\title{
Larvicidal and Oviposition Activity of Against Vector Aedes Aegypti and Molecular Docking Studies of Metabolites from the Crude Extract of the Endophytic Fungus Aspergillus Sp. Isolated from Bertholletia Excelsa Humn. \& Bonpl.
}

Inana F. Araújo

Universidade Federal do Amapá: Universidade Federal do Amapa

Victor Hugo Marinho

Federal University of Amapá: Universidade Federal do Amapa

Iracirema S Sena

Universidade Federal do Amapá: Universidade Federal do Amapa

Jhone Curti

UNIFAP: Universidade Federal do Amapa

Ryan S. Ramos

UNIFAP: Universidade Federal do Amapa

Ricardo M.A Ferreira

UNIFAP: Universidade Federal do Amapa

Raimundo N. P. Souto

Federal University of Amapá: Universidade Federal do Amapa

Irlon Ferreira ( $\boldsymbol{D}$ irlon.ferreira@gmail.com )

Universidade Federal do Amapa https://orcid.org/0000-0002-4517-0105

\section{Research Article}

Keywords: Amazonian biodiversity, Aedes aegypti, Acetylcholinesterase enzyme, Endophytic fungus.

Posted Date: June 3rd, 2021

DOI: https://doi.org/10.21203/rs.3.rs-535443/v1

License: (c) (i) This work is licensed under a Creative Commons Attribution 4.0 International License.

Read Full License 


\section{Abstract}

This work showed the crude extract of the endophytic fungus Aspergillus sp, isolated from the almonds of Bertholletia excelsa Humn \& Bonlp collected in the Brazilian Amazon, oviposition deterrent, and larvicidal activity of against Aedes aegypti. In the oviposition deterrence test was observed that females able to lay eggs preferred the control oviposition sites (46.6\%), suggesting the extract also could repel the oviposition. Futhermore, the extract showed larvicidal activity with $\mathrm{LC}_{50} 26.86 \mu \mathrm{g} / \mathrm{mL}$ at 24 hours and $18.75 \mu \mathrm{g} / \mathrm{mL}$ at 48 hours. Molecular docking studies were carried out to elucidate the mechanism of action of the compounds identified against the enzyme acetylcholinesterase. The compound Aspergillol $B$ was a potent larvicide with potential for inhibition for the acetylcholinesterase enzyme $(-7.74 \mathrm{Kcal} / \mathrm{mol})$. These unprecedented results reported indicate that the secondary metabolites obtained from crude extract of Aspergillus sp. present useful biological potential against vectors of public health importance and antibiotic-resistant bacteria.

\section{Introduction}

Aedes aegypti is the primary transmitter of human pathogens including Dengue, Chikungunya fever, and Zika virus; this species is closely associated with human habitation, and some epidemic patterns of the diseases transmitted by the species are caused by seasonal changes that affect its development, reproduction, and abundance (Kraemer et al., 2015; Pascini et al., 2012; Pliego-Pliego et al., 2020).

According to the Ministry of Health - Brazil (2020) (Ministério da Saúde, 2020), 390.684 probable cases of dengue were reported in Brazil until the 11th week of the year 2020, 11.453 cases of chikungunya, and 1.395 cases of zika virus, evidencing an increased number of these diseases in 2020.

Considering that there is no vaccine or medication available for the treatment of dengue or the other diseases transmitted by this vector, the main form of control available is controlling the vector population (Pliego-Pliego et al., 2020). The eradication of these mosquitoes is usually performed using organophosphate insecticides and pyrethroids; however, the continuous use of these compounds has selected resistant vector populations. Besides that, the low biodegradability of the current insecticides and larvicides can potentially lead to a long-term adverse effect on human health (Macari et al., 2002; Smith et al., 2016; Yang et al., 2020). Currently, there is a growing demand for new substances from natural sources, such as microorganisms (fungi and bacteria) and medicinal plants. These compounds are intensively explored in search of new bioactive metabolites (Mookherjee et al., 2020), including against the larvae of the Ae. aegypti (Araújo et al., 2020; Pradeep et al., 2015; Revathi et al., 2013).

The plant species Bertholletia excelsa, popularly known as Brazil-nut, is a species found throughout the Amazon region from countries such as Brazil, Bolivia, Peru, Colombia, Venezuela, Guyana, and it is considered a threatened species (Baldoni et al., 2020). B. excelsa is one of the most important species in the Amazon, and its wood and almonds are highly appreciated both in Brazil and abroad (Azevedo; and Luiz Marcelo Brum Rossi; Roberval Monteiro Bezerra de Lima, 2008). 
Endophytic fungi are microorganisms capable of colonizing the interior of plant tissues without causing damage to them (Strobel, 2012); this interaction becomes favorable for the host, as it can boost their tolerance to abiotic stress (Patil et al., 2016). Fungi are found in almost all vascular plants, seaweed, mosses, and ferns studied so far, and frequently, hundred species of them can be isolated from a single plant (Chapla et al., 2013). In this sense, the study of the secondary metabolites produced by their vast biodiversity fungal is of notorious relevance for the discovery of new products for biotechnological, industrial, medicinal, and agrochemical applications (Patil et al., 2016; Rana et al., 2020).

Molecular docking is an intensive and prominent computational method in the drug discovery process. The virtual sorting followed by docking has become one of the most important methods to improve efficiency in the Search for new molecules. The benefit of docking is to identify how the ligands bind at the enzyme or receptor binding site through specific key interactions and to predict the binding affinity between protein-ligand complexes (Gupta et al., 2020).

According to (Gubiani et al., 2019), fungi belonging to the genus Aspergillus is well known and investigated for synthesizing secondary metabolites with diverse biological effects, considering that Amazon has the most exceptional biodiversity on the planet and because it has favorable conditions for proliferation and adaptation of new microorganism species - including temperature, humidity, and organic residues -, the search for new chemical compounds for pharmaceutical, cosmetic, and food industry in this biome has considerable potential. Hence, this work aimed to obtain and evaluate the larvicidal activity and the effects on oviposition of the crude extract from the endophytic fungus Aspergillus sp. isolated from the chestnut of B. excelsa against Ae. Aegypti and mechanism of action the secondary metabolites with molecular docking studies.

\section{Material And Methods}

\subsection{Isolation and identification of the endophytic fungus Aspergillus sp (BIORG 9)}

The almonds of Bertholletia excelsa were collected in the area located 1 - W $52^{\circ} 18^{\prime} 20.976$ " and S $0^{\circ}$ $33^{\prime} 44.44$ " and 2 - W $51^{\circ} 57^{\prime} 53.338$ " and S $0^{\circ} 25^{\prime} 21.39$ ". The endophytic fungus used in this study was isolated from the almond and stored according to the protocol described by (Holanda et al., 2019).

The initial identifications were based on direct observation through an optical microscope (OLYMPUS ${ }^{8}$ BX41), these observations had morphological aspects as a criterion (K. et al., 1972; Visagie et al., 2014). The endophytic fungus (Biorg 9 - Aspergillus sp.) Used in this work was identified by conventional and molecular methods at the Pluridisciplinary Chemical, Biological and Agricultural Research Center (CPQBA, https: //cbmai.cpqba. Unicamp.br) at Universidade Estadual de Campinas (UNICAMP), SP, Brazil.

\subsection{Cultivation in solid and liquid medium of the endophytic fungus Aspergillus sp.}


The strain of the endophytic fungus was grown in a solid culture medium BDA (potato-dextrose-agar), then the material was sterilized in an autoclave (Phoenix, AV50) at $121^{\circ} \mathrm{C}$ for 20 minutes then the sterile medium was poured into plates Petri. After 24 hours, the petri dishes containing agar extract (2\%) were inoculated with spores of the fungus Aspergillus sp. using an inoculation needle through a central insertion point, the strain was then incubated at $28^{\circ} \mathrm{C}$ (DBO, LACADEMA, model LUCA-161/03) as described by (Holanda et al., 2019) during the 7-day period.

After the activation period, the fungus was placed to grow in $200 \mathrm{ml}$ of malt medium (2\%) at pH 7.0 in $500 \mathrm{ml}$ Erlenmeyer flasks .... Inoculations were performed with four circular discs ( $0.5 \mathrm{~cm}$ in diameter) from a solid culture. Each Erlenmeyer flask was incubated on an orbital shaker for 10 days $\left(28^{\circ} \mathrm{C} \pm 2^{\circ} \mathrm{C}\right.$, $160 \mathrm{rpm}$ ). The growth of the mycelial mass in liquid medium was performed in quintuplicate.

\subsection{Obtaining the secondary metabolite from the mycelial mass of the fungus Aspergillus sp.}

After the period of growth of the mycelial mass in the period of 10 days, $60 \mathrm{~mL}$ of ethyl acetate was added to each Erlenmeyer, kept in vigorous magnetic stirring for 30 minutes. This process is carried out so that cell lysis occurs, then the mixture was filtered. The aqueous phase was extracted with $99.5 \%$ ethyl acetate $(3 \times 60 \mathrm{~mL})$, the organic phase being filtered and the excess solvent being removed under reduced pressure on a rotary evaporator.

\subsection{Identification of metabolites produced by the endophytic fungus Aspergillus sp. by LC-MS / MS}

The metabolites of Aspergillus sp. were quantified by High Performance Liquid Chromatography with mass spectrometer (LC-MS). The extract was solubilized in $1 \mathrm{ml}$ of ethanol / water 1: 1 and eluted in a C18 column (500mg).

The conditions of the equipment were controlled and analyzed by LC-DAD-MS using an LC-DAD-ESI system consisting of a shimadzu HPLC 20A equipped with an LC-20AD quaternary pump, an SPD-M20A photodiode array detector, a thermostated SIL20A autosampler and a CTO-20 column compartment, coupled to a Brucker Ion Trap, with a heated ESI source. Mass spectra were acquired in negative and positive modes in the range of $100-1000 \mathrm{~m} / \mathrm{z}$, in separate series. The operational standards were: source source $4.5 \mathrm{kV}$ coating gas $9.00 \mathrm{~L} /$ min dry gas, 40 psi nebulizer and dry temperature $300^{\circ} \mathrm{C}$. Data analysis was performed using Data Analysis software. The elution gradient was carried out with water / $0.1 \%$ formic acid and acetonitrile / $0.1 \%$ formic acid.

\subsection{Larvicidal bioassay}

The larvae of Ae. aegypti, the used Rokeffeller colony, are from the Arthropod Laboratory of the Federal University of Amapá (ARTHROLAB), all larvae used were 3 stage. They were kept in standard weather conditions with a temperature of $25 \pm 2^{\circ} \mathrm{C}$ and relative humidity of $75 \pm 5 \%$ and photoperiod of 12 hours according to the World Health Organization (WORLD HEALTH ORGANIZATION, 2005). 
The extracts were prepared in different concentrations $(45,35,20,10$ and $5 \mu \mathrm{g} / \mathrm{mL})$ solubilized in DMSO $(0.5 \%)$. In each bioassay was used 10 larvae in controlled conditions $\left(25 \pm 2^{\circ} \mathrm{C}\right)$. The distilled water and DMSO $(0.5 \%)$ were used with negative controls. All assays were performed in quintuplicate (de Araújo et al., 2018).

The content of mortality count was carried out in periods of 24 and 48 hours after exposure to the larvae solutions. They were considered dead larvae were not able to reach the water surface (Rodrigues et al., 2014) and using the readings was possible to establish the lethal concentrations ( $\mathrm{LC}_{50}$ and $\left.\mathrm{LC}_{90}\right)$ by probit analysis. All bioassay experiments were conducted according to standard (World Health Organization, 2005).

\subsection{Oviposition-deterrence test}

The oviposition-deterrence effect of the acetyl extract of the endophytic fungus Aspergillus sp. in the laying of eggs. Ae. aegypti has been studied in 50 pregnant females (fed with blood) in $40 \times 40 \times 40 \mathrm{~cm}$ opposition cages under conditions of $25 \pm 2^{\circ} \mathrm{C}$ and relative humidity of $75 \pm 5 \%$ and a 12 -hour photoperiod according to WHO. The cages contained dark ovitraps with extract at concentrations of 45 , 35 and $20 \mu \mathrm{g} / \mathrm{mL}$ and control with distilled water and DMSO (0.5\%). The test was done in quadruplicate and the number of eggs was rated with 48 hours.

\subsection{Statistical analysis}

For larvicidal activity the lethal concentrations $\left(\mathrm{LC}_{50}\right.$ and $\left.\mathrm{LC}_{90}\right)$ were determined after 24 and $48 \mathrm{~h}$ of incubation and calculated using Probit analysis with StatGraphics Centurion. To evaluate the ovipositiondeterrence test, an analysis of variance (ANOVA) was performed with Turkey to determine if there is a significant difference between concentrations and control with GraphPad Prism 8.0.

\subsection{Molecular docking simulations}

In this stage, the molecules were optimized by computational method DFT B3LYP 6-31G** (Braga and Valle, 2007; Lo et al., 2017; Siegel et al., 2017; Warren et al., 2016) and used as an input file for molecular docking simulations, in order to evaluate the score of the energy function through the free-energy $(\Delta G)$ of molecule interaction from virtual ligand-based screening as well as the analysis of conformations, mode of interaction and binding affinity with the selected receptors.

\subsection{Selection of enzymes and inhibitors}

Crystallographic structure of recombination Human acetylcholinesterase (AChE) complexed with -(-) galantamine (GNT), elucidated by X-ray diffraction was downloaded from the Protein Data Bank (PBD) with code $4 \mathrm{EY} 6$ and a solution of 2,4 $\AA$ (Cheung et al., 2012). The crystallographic structure of Drosophila melanogaster acetylcholinesterase (AChE) in complex with the tacrine derivative, 9- (3-iodobenzylamino) -1,2,3,4-tetrahydroacridine (140) was downloaded from the Protein Data Bank (PDB), with PDB ID 1QON and resolution of $2.7 \AA$ (Harel et al., 2000). The crystallographic structure of juvenile hormone complexed with methyl - (2E, 6E) -9 - [(2R) -3,3-dimethyloxiran-2-yl] -3,7-dimethylnona-2,6-dienoate, (JH3), was 
downloaded with the code PDB 5V13, with a resolution of $1.87 \AA$ (Kim et al., 2017). The crystallographic structure of juvenile hormone complexed with methyl - (2E, 6E) -9 - [(2R) -3,3-dimethyloxiran-2-yl] -3,7dimethylnona-2,6-dienoate, (JH3), was downloaded with the code PDB 5V13 with a resolution of $1.87 \AA$ (Kim et al., 2017).

\subsection{Virtual high-throughput screening (vHTS)}

Heteroatoms, co-crystallized ligand and water molecules were removed using the Discovery Studio 5.0 software. The validation of molecular docking protocols was performed by overlapping the elucidated crystallographic structure (experimental) with the generated model (theoretical), that is, comparison between the crystallographic ligand and the best conformation obtained with molecular docking based on the value of the Root Mean Square Deviation (RMSD).

The $\mathrm{X}, \mathrm{Y}$ and $\mathrm{Z}$ coordinates of the receptors were determined according to the average region of the active site. The coordinates used for the center of the grid can be seen in Table 1.

\subsection{Biological Activity Predictions of the molecules}

The Prediction of Activity Spectra for Substances (PASS) were performed while using the webserver http://www.pharmaexpert.ru/passonline. PASS makes it possible to relate effects of the molecule based entirely on the molecular formula using Multilevel Neighbors of Atoms (MNA) descriptors, suggesting that biological activity is in function of its chemical structure (Ferreira et al., 2017; Kirchmair et al., 2015). Only molecules with insecticidal and anticholinesterase activities were selected at this stage.

\section{Results And Discussion}

\subsection{Endophyte species identification}

The ITS fragments and the beta-tubulin gene were successfully amplified and sequenced from the samples' genomic DNA. The fungus sample Biorg 09 (Fig. 1) named CPQBA 1929/19 DRM 03 was sequenced and identified as Aspergillus sp. as the partial sequence of the beta-tubulin gene had $100 \%$ similarity with the corresponding sequences from the Aspergillus genus deposited in GenBank and CBSKNAW databases. The genetic distance analysis retrieved the CPQBS 1929/19 DMR 03 sample in a low resolution cluster (68\%) with the type strain of the species A. violaceofucus CBS 123 and A. japonicus CBS 11451, the latter being a synonym for the first, thus, the results of the analyzes carried out in the databases and phylogeny suggest the final identification as Aspergillus sp., within the nigri section (Fig. 2).

The Aspergillus genus is found in all areas throughout the world and has a high economic and social impact. In this genus are found species used in biotechnology for the production of metabolites with 
useful applications, such as antibiotics, organic acids, medicines or enzymes, and food fermentation agents (Samson et al., 2014).

The nigri section of the Aspergillus genus, commonly known as black Aspergillus, was formerly identified and classified based on morphology, according to Yokoyama et al. (Yokoyama et al., 2001). However, this section is one of the most challenging groups for identification, and several taxonomic schemes have already been proposed. Currently, molecular methods are used for this purpose (Varga et al., 2011).

Ferranti et al. (Ferranti et al., 2018), studying the fungal diversity on the surface of Vitis labrusca and hybrid grapes, reported $13.9 \%$ of the Aspergillus genus, and species of the nigri section were found in most samples. The molecular characterization of Aspergillus in grapes showed a genetic divergence between strains of this genus and reported an ochratoxigenic strain, often isolated from grapes, called $A$. tubingensis (Martínez-Culebras et al., 2009). It is observed that the nigri section presents a high diversity, as was also observed in this study.

\subsection{LC-MS/MS analysis}

The LC-MS/MS is used for the obtention of spectra from the products' ions to assess the chemical structure of its compounds. It can analyze neutral losses and simultaneous product ions from a single dataset (Renaud et al., 2017). Employing this technique, we identified several metabolites produced by Aspergillus sp. isolated from Bertholletia excelsa, as shown in Table 2.

More than 330 species of fungi are known in the Aspergillus genus, found in different ecosystems; this genus has a high impact on the health of humans, animals, and plants. The species of this genus produce a remarkable number of secondary metabolites with the most varied biological activities reported (Soltani, 2016).

The crude acetyl extract of Aspergillus sp. (Biorg 09) isolated from B. excelsa presented several molecules, some of them already reported to have biological activities with potential applications in the treatment of infectious diseases, diabetes, Alzheimer, physiological disorder and are a source of antioxidant agents (Mikawlrawng, 2016). Some of the metabolites found, like enniatins, are characteristic of Fusarium species (Jonsson et al., 2016).

Cyclodepsipeptides (enniatin) were described more than 60 years ago, and also have broad biological activities like antitumor, anthelmintic, insecticide, antibiotic, antifungal, immunosuppressant, antiinflammatory and antimalarial (Sivanathan and Scherkenbeck, 2014). It is important to note that this class of metabolite is identified mainly in fungi of the genus Fusarium (Renaud et al., 2017). Some of their biological activities are attributed to the capacity to increase the flow of alkali metal ions through biological membranes (Ivanova et al., 2006).

Aspernolide, an aromatic butenolide compound, is a metabolite found in some endophytic species, such as in the marine endophytic fungus $A$. terreus (Parvatkar et al., 2009). Ibrahim et al., 2015 evaluated the antimicrobial activity of butyrolactones isolated from this endophytic fungus against $S$. aureus, and the 
and anti-leishmanial activity against the promastigote phase of Leishmania donavi. Another relevant substance identified in Aspergillius sp. was aspulvinone, already reported to be an inhibitor of the viral neuraminidase H1N1 (Gao et al., 2013), and a potent antioxidant agent (Zhang et al., 2015).

The compound paclitaxel, known as taxol, is a well-known and effective drug used in the chemotherapy of cancers in the head, neck, breast, lung, bladder, ovary, and cervix. It is a substance produced originally by plants from the genus Taxus. However, the symbiosis between plant and fungi made some endophytic fungi also produce this molecule (Kumar et al., 2019).

According to Zhu (Zhu and Chen, 2019), the extraction of paclitaxel from endophytic fungi has proven to be an effective alternative way to get the drug. Among endophytic fungi, several species, including Aspergillus fumigatus, Pestalotiopsis microspora, Alternaria brassicicola, are reported to produce this compound (Gill and Vasundhara, 2019; Kumar et al., 2019; Subban et al., 2019; Zhu and Chen, 2019), and our results indicate that Aspergillus sp. isolated from Brazil-nut tree also can.

\subsection{Larvicidal effect of the extract and oviposition deterrence test against Aedes aegypti}

In the larvicidal test against Ae. aegypti, it was possible to observe that the extract had effective larvicidal activity in 24 and 48 hours. With a mortality of $84 \%$ at $45 \mu \mathrm{g} / \mathrm{mL}$ and $8 \%$ at $5 \mu / \mathrm{mL}$ in 24 hours; $96 \%$ at 45 $\mu / \mathrm{mL}$ and $26 \%$ at $5 \mu \mathrm{g} / \mathrm{mL}$ in 48 hours. Thus demonstrating the extract presents a set of compounds with potential use for the control of this vector of public health importance.

We further evaluated the values of lethal concentrations (LC) $50 \%$ and $90 \%$ for 24 and 48 hours (Table 4). For $24 \mathrm{~h}$, the $\mathrm{LC}_{50}$ was $26.86 \mu \mathrm{g} / \mathrm{mL}$, and the $\mathrm{CL}_{90}$ was $47.55 \mu \mathrm{g} / \mathrm{mL}$; for $48 \mathrm{~h}$, the $\mathrm{LC}_{50}$ was $18.75 \mu \mathrm{g} / \mathrm{mL}$, and the $\mathrm{LC}_{90}$ was $38.93 \mu \mathrm{g} / \mathrm{mL}$. These values show a remarkable efficiency of the extract that is timeand dose-dependent.

As stated by Geris et al., 2008, plants' secondary metabolites have a range of biological activities due to their structural diversity. These molecules are a continuous source of inspiration for drug discovery. Nevertheless, fungi also produce secondary metabolites with the most varied activities reported, such as antimalarial (Isaka et al., 2007), antibacterial (Hu et al., 2008), antiviral (Linnakoski et al., 2018), antifungal (Hoffman et al., 2008), and leishmanicidal (Cota et al., 2018).

De acordo com Balumahendhiran et al. (2019) also tested the larvicidal activity of the crude extracts from fungi of the Aspergillus genus ( $A$. flavus and A. fumigatus). The extract was tested against three diseasetransmitting mosquito species: Anopheles stephensi, Culex quinquefasciatus, and Aedes aegypti. For the extract from $A$. flavus, the authors reported the following (against $A$ e. aegypti): for 24 hours, the $\mathrm{LC}_{50}$ was $18.01 \mu \mathrm{g} / \mathrm{mL}$, and the $\mathrm{LC}_{90}$ was $31.05 \mu \mathrm{g} / \mathrm{mL}$; for 48 hours, the $\mathrm{LC}_{50}$ was $50.39 \mu \mathrm{g} / \mathrm{mL}$, and the $\mathrm{LC}_{90}$ was $82.26 \mu \mathrm{g} / \mathrm{mL}$. For the extract from A. fumigatus, in turn, the authors reported: for 24 hours, the $L_{50}$ was $14.79 \mu \mathrm{g} / \mathrm{mL}$, and the $\mathrm{LC}_{90}$ was $35.40 \mu \mathrm{g} / \mathrm{mL}$; for 48 hours, the $\mathrm{LC}_{50}$ was $35.37 \mu \mathrm{g} / \mathrm{mL}$, and the $\mathrm{LC}_{90}$ was 
$73.30 \mu \mathrm{g} / \mathrm{mL}$. Overall, the results of these authors corroborate our's and emphasize the potential of using fungi metabolites for the control of public health importance vectors.

An ethyl acetate extract from the mycelium of the entomopathogenic fungus Beauveria bassiana was tested against the four larval stages (LI, L2, L3, and L4) of Ae. aegypti by Ragavendran et al.

(Ragavendran et al., 2017). The authors observed the larvae mortality within 24 hours of exposure to different concentrations $(50,100,150,200,250$, and $300 \mu \mathrm{g} / \mathrm{mL})$ and reported $\mathrm{LC}_{50}$ values of $62.50(\mathrm{~L} 1)$, 52.89 (L2), 58.60 (L3), and 47.12 (L4) $\mu \mathrm{g} / \mathrm{mL}$; and $\mathrm{LC}_{90}$ values of 314.82 (L1), 236.18 (L2), 247.53 (L3), and $278.52(\mathrm{~L} 4) \mu \mathrm{g} / \mathrm{mL}$. While the authors reported for $\mathrm{L} 3$ an $\mathrm{LC}_{50}$ of 58.60 and an $\mathrm{LC}_{90}$ of $247.53 \mu \mathrm{g} / \mathrm{mL}$, our results of $\mathrm{LC}_{50}$ and $\mathrm{LC}_{90}$ were 26.86 and $47.55 \mu \mathrm{g} / \mathrm{mL}$, respectively, suggesting that the extract from Aspergillus sp. isolated from B. excelsa had a higher potential against Ae. aegypti larvae.

According to Montenegro et al. (Montenegro et al., 2006), extracts show promising activity when the mortality is equal or higher than $75 \%$ at $250 \mu \mathrm{g} / \mathrm{mL}$. For Cheng et al. (Cheng et al., 2003), potential substances need $\mathrm{LC}_{50}$ values lower than $100 \mu \mathrm{g} / \mathrm{mL}$ to be considered a good larvicidal agent. Here, $84 \%$ of mortality was observed within 24 hours at $45 \mu \mathrm{g} / \mathrm{mL}$. The discovery of new compounds to fight $A e$. aegypti is attractive since, in the last 15 years, populations of this mosquito developed resistance to the main organophosphate and pyrethroid insecticides in several countries (Rocha et al., 2015). Another disadvantage of the current insecticides is the toxicity caused to the environment.

The insecticidal activity of fungal products is not always attractive for commercial use. For instance, Pradeep et al. (Pradeep et al., 2015) evaluated the larvicidal activity of the isoquinoline-type pigment produced by the fungus Fusarium moniliforme against Ae. aegypti and An. stephensi. They reported $\mathrm{LC}_{50}$ of $237.0 \mu \mathrm{g} / \mathrm{mL}$ and $335.6 \mu \mathrm{g} / \mathrm{mL}$ in 24 hours, respectively; these are considered high values for vector control.

In addition to using metabolites produced by endophytic fungi, another approach is using a suspension of conidia, or an association of conidia and neem oil activity against Ae. aegypti larvae (Gomes et al., 2015). This demonstrates that using fungi conidia and metabolites, either isolated or associated, can be a valuable tool for vector control and other applications.

In our study, it was also possible to observe external structure changes in the larvae caused by the crude extract of Aspergillus sp. (Fig. 3). It is noted a loss of color and loss of segmentation in the treated larva (Fig. 3b), unlike in the control group (Fig. 2a), where is observed segmented abdomen structures (AB) and normal coloration under the optical microscope. We suggest that the extract of Aspergillus sp. could interact with the larval chitin cuticle, causing changes that resulted in their death. It is essential to highlight that these changes were not observed in the control group, treated with water and DMSO.

According to (Ureña et al., 2019), several mechanisms may be involved in the mortality of Ae. aegypti larvae by insecticides. Some substances act directly on the central nervous system; others can lead to cell damage and, consequently, the death of the larvae because the digestive system tries to eliminate the 
compound, leading to extrusion of the peritrophic matrix (Valotto et al., 2011). Red seaweed extract was also reported to affect the larvae's external structure. When compared to the control, the larvae had progressive deformities in their lateral hair, anal papillae, distorted body, loss of color, and changes in the respiratory siphon (Deepak et al., 2019).

These external larval structure changes have also been reported as one of the mechanisms of larvae death in other studies, along with a darker or pale body, cuticle changes, and other larvae aberrations (Araújo et al., 2020; Kuo et al., 2015). The histopathological effect of spores from the fungus Aspergillus clavatus against Culex quinquefasciatus was also assessed (Bawin et al., 2016). The authors reported that the spores adhered to the external cuticle and the larval digestive tract; this accumulation caused gradual destruction of the digestive epithelium, muscular and connective tissues, and the epidermis right below the cuticle, which together may be accountable to larval death.

In the oviposition deterrence test, it was observed that pregnant females of Ae. aegypti preferred laying eggs (46.6\%) in the control oviposition site with water and DMSO $(0.5 \%)$. There was no significant difference among the different concentrations of the extract (ANOVA, $p>0.05$ ). However, there was a statistical divergence between the extract doses $20,35,45 \mu / \mathrm{mL}$ compared to the control.

According to Soonwera and Phasomkusolsil (Soonwera and Phasomkusolsil, 2017), the application of oviposition repellent is an effective strategy for controlling mosquito populations. These authors tested the effect of the essential oil from Zanthoxynlum limonella Alston (Rutaceae) against the oviposition of Ae. aegyptiand $C x$. quinqufasciatus. They reported that a solution made of $10 \%$ of this oil dissolved in ethanol $70 \%$ had $100 \%$ repellency against $A$ e. aegypti and $99.53 \%$ against $C x$. quinquefasciatus. In the environments receiving insecticides, these agents act as modulators of insect growth (Tilak et al., 2005), by preventing oviposition and consequent population boost, which is especially relevant against insects of medical importance, like Ae. aegypti.

In a recent study by Michaelakis et al., 2020, the authors tested an aqueous suspension of spinosad - a natural bioinsecticide toxic to pest and vectors - against $C x$. Pipiens molestus larvae. However, there was no significant difference between spinosad compared to the control, different from our study, where the crude extract, besides being effective against the larval stage, also could repel the oviposition of pregnant females in 48 hours.

Other natural products also have shown promising results in the oviposition deterrence test against $A e$. aegypti, such as the extract of Melanochyla fasciculiflora (Zuharah et al., 2015), the essential oil, and aqueous extract of Alpinia purpurata (Santos et al., 2012). Besides being repellent against the oviposition, these products also were effective against the larval stage. Such compounds can potentially be used in the water for vector control by preventing pregnant females from depositing eggs, or by killing the larvae.

\subsection{Molecular docking simulations and biological activity}

Retrieving the shapes of GNT inhibitors, 140 and HJIII, it was possible to validate the molecular docking protocols, calculating the RMSD values of $0.36,0.78$ and $0.94 \AA$, respectively. According to (Gowthaman 
et al., 2008; Ramos et al., 2019), the binding mode predicted using docking indicates that when the RMSD is less than $2.0 \AA$ in relation to the crystallographic pose of a respective ligand, the validation is considered satisfactory. The best results of the validation can be seen in Fig. 3 .

The residues of active sites for GNT (PDB 4EY6) are around the $a$-helix between the amino acid residues $336-338$ and in the $\beta$-leaf between the amino acid residues $85-87,121-124$ and $202-203$. For the ligand it was possible to notice common hydrogen bonds with the residues Tyr124, Glu202 and Ser203. A hydrophobic interaction with residues Trp86, Gly121 and Tyr337 is also highlighted (Cheung et al., 2012).

Generated docking pose made it possible for the ligand to also interact with the amino acid residues of the 140 active site (PDB ID 1QON) around the $\alpha$-helix between the Thr369-Asp375 amino acid residues and included in the $\beta$-leaf between the amino acid residues lle82-Trp83. In the ligand, it is possible to observe hydrophobic interactions with the vast majority of residues in Tyr71, Trp83, Tyr370, Phe371, Tyr374 and His380, results that are in agreement with the studies by (Harel et al., 2000).

The interaction sites with the JHIII (PDB 5V13) are around the $a$-helix between the amino acid residues $30-38,45-51,60-71,123-130,132-136,138-143$ and $280-286$ for $\beta$-leaf between amino acid residues $52-55,72-73,144-145$ and $276-279$. For the ligand, it is possible to observe hydrophobic interactions with all amino acid residues (Kim et al., 2017).

In order to assess whether the interactions showed greater binding affinity than the specific control ligands (140, GNT and JHIII) for acetylcholinesterase from different organisms (Drosophila melanogaster and Homo sapiens) and juvenile mosquito hormone (Ae. aegypti) it was observed that of molecules submitted to docking, only Aspergillol B, Aspernolide A and Aspulvinone D presented values greater than or equal to the negative controls used. The binding affinity values of the new inhibitors at the acetylcholinesterase receptor can be seen in Fig. 4 .

Inhibitors complexed with Aspergillol B $(-8.2 \mathrm{Kcal} / \mathrm{mol})$ and Aspulvinone C $(-8.5 \mathrm{Kcal} / \mathrm{mol})$ at the acetylcholinesterase receptor showed values close to the pyriproxyfen control, whereas Aspulvinone $D$ had a higher value due to the binding affinity of $-9.3 \mathrm{Kcal} / \mathrm{mol}$. Therefore, it is suggested that the molecule is promising for insecticidal activity, since it presents interactions similar to the controls used in the docking study. Thus, comparing the affinity values of Aspulvinone D molecule to GNT control, a difference of $\pm 0.7 \mathrm{Kcal} / \mathrm{mol}$ is observed, and to the others a variation of \pm 1.8 to $\pm 1.5(\mathrm{Kcal} / \mathrm{mol})$.

When the study was related to the organism of Drosophila melanogaster, the Aspernolide A molecule showed a binding affinity of $-9.9 \mathrm{Kcal} / \mathrm{mol}$, followed by Aspergillol B with $-9.5 \mathrm{Kcal} / \mathrm{mol}$ compared to controls 140 and pyriproxyfen (PDB ID 1QON), according to Fig. 5B.

140 exhibited a binding affinity of $-13.3 \mathrm{Kcal} / \mathrm{mol}$ higher than pyriproxyfen of $-9.0 \mathrm{Kcal} / \mathrm{mol}$. The Aspergillol B and Aspernolide A molecules showed a higher binding affinity value than the pyriproxyfen (control) used in molecular docking. Thus, when comparing the Aspernolide A compound with the 140 
control, a difference of $\pm 3.4 \mathrm{Kcal} / \mathrm{mol}$ was observed, while a variation of $\pm 3.8 \mathrm{Kcal} / \mathrm{mol}$ was observed in Aspergillol B, as shown in Fig. 5B.

In relation to the $5 \mathrm{~V} 13$ complex (Ae. aegypti), the Aspergillol B and (+)-N-deoxymilitarinone showed a higher binding affinity value compared to JHIII (control) used with a value of -9.4 and $-9.7 \mathrm{Kcal} / \mathrm{mol}$, respectively. The results of the affinity values can seen in Fig. 5.

$\mathrm{JHIll}$ showed a binding affinity of $-8.9 \mathrm{Kcal} / \mathrm{mol}$ lower than the pyriproxyfen of $-10.6 \mathrm{Kcal} / \mathrm{mol}$. However, a binding affinity variation of $\pm 1.2 \mathrm{kcal} / \mathrm{mol}$ of Aspergillol B and $\pm 0.9 \mathrm{Kcal} / \mathrm{mol}$ of $(+)-N$-deoxymilitarinone is observed compared to pyriproxyfen (control).

Based on the data found, we propose that the molecules present in the extract of the fungus Aspergillus sp. are able to bind to the active sites of the proposed targets. The Aspulvinone $D$ molecule has a greater affinity for the human acetylcholinesterase active site, while Aspernolide A has a greater affinity for the active site of the acetylcholinesterase binding protein in e (+) - $\mathrm{N}$-deoxyilitarinone for the youth hormone. Aspergillol $\mathrm{B}$ was the common molecule for both cases, considering the mode of binding in all study targets, thus the promising dual effect is observed, both for the inhibition of the enzyme acetylcholinesterase (human and insect) as well as the juvenile hormone.

Molecules with insecticidal potential can irreversibly inhibit the production of acetylcholinesterase, such an enzyme is responsible for the hydrolysis of acetylcholine (Ach) which ends the propagation of the nervous impulse. The inhibition of the enzyme acetylcholinesterase is the initial mechanism for a substance considered to have a potential insecticide in the larval phase, considering this knowledge cited by several authors it is essential to observe interactions at the active site of the acetylcholinesterase complex, in which three important characteristics are present in order to understand the mechanism of elucidation of the biological action of enzyme production.

In the Aspulvinone $\mathrm{C}$ and Aspulvinone $\mathrm{D}$ molecules used in the docking study, similar interactions were detected in the control molecules in relation to the acetylcholinesterase active site, located around the ahelix between the amino acid residues Ser203, Tyr337 and Phe338 and in the $\beta$-leaf between the Trp86, Gly121 and His447 residues, as shown in Fig. 6.

Figure 6-Interactions of GNT (A), Pyriproxyfen (B) and potential inhibitors Aspulvinone C (C) and Aspulvinone D (D) with active site of the acetylcholinesterase receptor. *

*Dashed black lines indicate hydrogen bonds, saline bridges and interactions with metal. Solid green lines show hydrophobic interactions and the dashed green lines show $\pi-\pi$ and $\pi$-cations interactions.

According to (Meriç, 2017) at the AChE active site, the catalytic triad (Ser203, Glu334 and His447) is found in the lower portion of the active site, surrounded by three important parameters for catalytic activity: the acyl sac (residues of Phe295, Phe297 and Phe338), the oxy-anion channel (nitrogen from the main chain of residues Gly121, Gly122 and Ala204) and the choline binding site (Trp86 eTyr337). The most significant contributions of the interactions in the docking study were observed in the Aspulvinone $\mathrm{C}$ 
molecule, in which the contribution of the catalytic triad represented by His447 and the connection with the Trp86 hill is notable. Other not so common interactions were also observed with the Tyr72 and Tyr341 residues, these interactions end up stabilizing the ligand in the active center of receptor. The increase in binding affinity, in turn, ends up inactivating the enzyme acetylcholinesterase by competition with an active site with GNT.

The interactions observed in controls 140 and pyriproxyfen in the docking study were also similar in the Aspergillol $B$ and Aspernolide A molecules in relation to the acetylcholinesterase site, located around the a-helix between the amino acid residues Tyr370-Tyr374 and the $\beta$-leaf in the residue Trp83, as shown in Fig. 7.

Interactions of potential inhibitors with the amino acid residues Trp71, Trp83, Tyr370, Phe371 and His480 of acetylcholinesterase are similar to those reported in the literature (Fournier et al., 1993; Gnagey et al., 1987). The best evaluated inhibitors in binding affinity parameters were Aspergillol B and Aspernolide $A$, considering that the interactions were similar to those observed in controls 140 and pyriproxyfen for Tyr71, Trp83, Tyr370 and Tyr374 residues, contributing to the increase in binding affinity. The less common interactions between the inhibitors were Glu80, Gly150 and Phe371, and these electrostatic contributions help stabilize the protein's active site.

Aspergillol B molecule with a free energy of $-7.74 \mathrm{Kcal} / \mathrm{mol}$ has a hydrogen bond with the amino acid residue Tyr370 and an $\pi-\pi$ interaction with Trp83, the latter being also similar at 140. Aspernolide A molecule with the greatest potential for insecticidal activity has greater free energy than the pyriproxyfen control $(-9.35 \mathrm{Kcal} / \mathrm{mol})$ and with $\pi-\pi$ interaction with a similar Tyr370, however, the interactions are more intense in the inhibitor favored by the reduction the distance. The conformation of inhibitors at the active site is influenced by the distances of interactions with amino acid residues.

In the juvenile hormone receptor complexed with $\mathrm{JHII}$, the Aspergillol B and (+) - N-deoxymilitarinone molecules had interactions similar to the control molecules present in the amino acid residues located around the a-helix between the amino acid residues Tyr33, Leu37, Val51, Val68 and Tyr129 and $\beta$-leaf between Trp53 and Phe144 residues, as shown in Fig. 8

The Aspergillol B molecule with a free energy of $-8.57 \mathrm{Kcal} / \mathrm{mol}$ has hydrophobic interactions with the Tyr33, Val51, Val65 and Ser69 residues and $\pi-\pi$ interactions with Trp33 and Trp53. The molecule with the greatest potential to inhibit the enzyme acetylcholinesterase is $(+)-N$-deoxymilitarinone, as it has significant similar interactions and free energy of $-11.79 \mathrm{Kcal} / \mathrm{mol}$ compared to the controls used. There are less common interactions for the Tyr129 and Tyr155 residues which contribute to greater stability of the molecule at the receptor.

In the complex of the juvenile hormone protein, the ligand $\mathrm{JHIII}$ is present in the binding pouch of the $\mathrm{N}$ terminal domain, the conformation of the crystal being identical to the three chains of the protein. In JHIII, the presence of an epoxy group located in the center of the domain is observed and a methyl ester is oriented towards the surface. The epoxy group forms hydrogen bonds with the phenolic hydroxyl of 
Tyr129 and the rest of the isoprenoid chain is surrounded by hydrophobic side chains including those of Phe144, Tyr64, Trp53, Val65, Val68, Leu72, Leu74, Val51 and Tyr33 [48].

Predicting the biological activity of molecules submitted via the web PASS server (Harel et al., 2000) resulted in the data shown in Table 3. The reference molecules (pyriproxyfen, 140, GNT and JHIII) showed insecticidal or similar activity, corroborating the results of the literature (Braga and Valle, 2007; Harburguer et al., 2009; Kim et al., 2017; Olmstead and LeBlanc, 2003; Paul et al., 2006; Sullivan and Goh, 2008).

In the molecules analyzed in the biological activity prediction study, only Aspergillol B showed a satisfactory prediction compared to the controls used in the molecular docking study, in which Pa was 0.187 and similar to other bioactive molecules known for insecticidal activity, acetylcholinesterase and acetylcholine inhibitor when $\mathrm{Pa}>\mathrm{Pi}$.

\section{Conclusion}

Results of this study suggest that metabolic from crude extract of endophytic fungus Aspergillus sp. isolated from Bertholletia excelsa was effective against drug-resistant bacteria strains of $S$. aureus, demonstrating that the crude extract of Aspergillus sp. can also be used as an antimicrobial agent. Moreover, the metabolites present in the extract are potential natural larvicides to control the vector $A e$. aegypti, the findings of the molecular docking study demonstrated the mechanism of action of the compound Aspergillol B by inhibiting the enzyme acetylinesterase $(-7.74 \mathrm{Kcal} / \mathrm{mol})$. Therefore, this compound can serve as a new class of product with environmentally friendly larvicidal activity.

\section{Declarations}

\section{Acknowledgements}

The authors would like to acknowledge the Research Support Foundation of the State of Amapá (Fundação de Amparo à Pesquisa do Estado do Amapá, FAPEAP; grant no. 34568.515.22257.28052017).

The Coordination for the Improvement of Higher Education Personnel - Brazil (CAPES), by the financing in part of the present work and to Pharmaceutical Innovation Graduate Program (PPGIF) for their financial support.

\section{References}

Araújo IF, Loureiro HA, Marinho, Ferreira IM et al (2020) Larvicidal activity of the methanolic, hydroethanolic and hexanic extracts from Acmella oleracea, solubilized with silk fibroin, against Aedes aegypti. Biocatal. Agric. Biotechnol. 24:101550. https://doi.org/10.1016/j.bcab.2020.101550

Azevedo CR, Rossi LMB, Lima RMB (2008) Comunicado Técnico 63: Castanha-do-Brasil (Bertholletia excelsa Humb. \& Bonpl), Empresa Brasileira de Pesquisa Agropecuária. 
https://doi.org/10.1002/9783527678518.ehg2013005

Baldoni AB, Teodoro LPR, Eduardo Teodoro P et al (2020) Genetic diversity of Brazil nut tree (Bertholletia excelsa Bonpl.) in southern Brazilian Amazon. For. Ecol. Manage. 458:117795.

https://doi.org/10.1016/j.foreco.2019.117795

Balumahendhiran K, Vivekanandhan P, Shivakumar MS (2019) Mosquito control potential of secondary metabolites isolated from Aspergillus flavus and Aspergillus fumigatus. Biocatal. Agric. Biotechnol. 21, 101334. https://doi.org/10.1016/j.bcab.2019.101334

Barnett, H.L., Hunter, B.B., 1972. Illustrated Genera of Imperfect Fungi. 241 p. https://doi.org/10.2307/3757954

Bawin T, Seye F, Boukraa S et al. (2016) Histopathological effects of Aspergillus clavatus (Ascomycota: Trichocomaceae) on larvae of the southern house mosquito, Culex quinquefasciatus (Diptera: Culicidae). Fungal Biol. 120:489-499. https://doi.org/10.1016/j.funbio.2016.01.002

Braga IA, Valle D (2007) Aedes aegypti: inseticidas, mecanismos de ação e resistência. Epidemiol. e Serviços Saúde 16:279-293. https://doi.org/10.5123/s1679-49742007000400006

Chapla VM, Biasetto CR, Araujo AR (2013) Endophytic fungi: An unexplored and sustainable source of new and bioactive natural products. Rev. Virtual Quim. 5:421-437. https://doi.org/10.5935/19846835.20130036

Cheng SS, Chang HT, Chang ST et al (2003) Bioactivity of selected plant essential oils against the yellow fever mosquito Aedes aegypti larvae. Bioresour. Technol. 89:99-102. https://doi.org/10.1016/S09608524(03)00008-7

Cheung J, Rudolph MJ, Burshteyn F, Cassidy MS et al (20120 Structures of human acetylcholinesterase in complex with pharmacologically important ligands. J. Med. Chem. 55:10282-10286. https://doi.org/10.1021/jm300871x

Costa JR, Castro ABC, Wandelli EV et al (2009) Aspectos silviculturais da castanha-do-brasil (Bertholletia excelsa) em sistemas agroflorestais na Amazônia Central. Acta Amaz. 39:843-850.

https://doi.org/10.1590/s0044-59672009000400013

Cota BB, Tunes LG, Maia DNB et al (2018) Leishmanicidal compounds of nectria pseudotrichia, an endophytic fungus isolated from the plant Caesalpinia echinata (Brazilwood). Mem. Inst. Oswaldo Cruz 113:102-110. https://doi.org/10.1590/0074-02760170217

De Araújo IF, De Araújo PHF, Ferreira IM et al (2018) Larvicidal effect of hydroethanolic extract from the leaves of Acmella oleracea L. R. K. Jansen in Aedes aegypti and Culex quinquefasciatus. South African J. Bot. 117:134-140. https://doi.org/10.1016/j.sajb.2018.05.008 
Deepak P, Balamuralikrishnan B, Park S, Sowmiya R (2019) Phytochemical profiling of marine red alga, Halymenia palmata and its bio-control effects against Dengue Vector, Aedes aegypti. South African J. Bot. 121:257-266. https://doi.org/10.1016/j.sajb.2018.11.011

Ferranti L, Fungaro MHP, Massi FP (2018) Diversity of Aspergillus section Nigri on the surface of Vitis labrusca and its hybrid grapes. Int. J. Food Microbiol. 268:53-60.

https://doi.org/10.1016/j.jffoodmicro.2017.12.027

Ferreira JV, Chaves GA, Marino BLB et al (2017) Cannabinoid Type 1 Receptor (CB1) Ligands with Therapeutic Potential for Withdrawal Syndrome in Chemical Dependents of Cannabis sativa. ChemMedChem 12:1408-1416. https://doi.org/10.1002/cmdc.201700129

Fournier D, Mutero A, Pralavorio M, Bride JM (1993) Drosophila acetylcholinesterase: Mechanisms of resistance to organophosphates. Chem. Biol. Interact. 87:233-238. https://doi.org/10.1016/00092797(93)90047-3

Gao H, Guo W, Wang Q, Zhang L (2013) Aspulvinones from a mangrove rhizosphere soil-derived fungus Aspergillus terreus Gwq-48 with anti-influenza A viral (H1N1) activity. Bioorganic Med. Chem. Lett. 23:1776-1778. https://doi.org/10.1016/j.bmcl.2013.01.051

Geris R, Da Silva IG, Da Silva HHG et al (2008) Diterpenoids from Copaifera reticulata ducke with larvicidal activity against Aedes aegypti (L.) (Diptera, Culicidae). Rev. Inst. Med. Trop. Sao Paulo 50:2528. https://doi.org/10.1590/S0036-46652008000100006

Gill H, Vasundhara M (2019) Isolation of taxol producing endophytic fungus Alternaria brassicicola from non-Taxus medicinal plant Terminalia arjuna. World J. Microbiol. Biotechnol. 35, 1-8. https://doi.org/10.1007/s11274-019-2651-8

Gnagey AL, Forte M, Rosenberry TL (1987) Isolation and characterization of acetylcholinesterase from Drosophila. J. Biol. Chem. 262, 13290-13298.

Gomes SA, Paula AR, Ribeiro A (2015) Neem oil increases the efficiency of the entomopathogenic fungus Metarhizium anisopliae for the control of Aedes aegypti (Diptera: Culicidae) larvae. Parasites and Vectors 8:1-8. https://doi.org/10.1186/s13071-015-1280-9

Gowthaman U, Jayakanthan M, Sundar D (2008) Molecular docking studies of dithionitrobenzoic acid and its related compounds to protein disulfide isomerase: Computational screening of inhibitors to HIV-1 entry. BMC Bioinformatics 9:1-10. https://doi.org/10.1186/1471-2105-9-S12-S14

Gubiani JR, Oliveira MCS, Neponuceno RAR (2019) Cytotoxic prenylated indole alkaloid produced by the endophytic fungus Aspergillus terreus P63. Phytochem. Lett. 32, 162-167. https://doi.org/10.1016/j.phytol.2019.06.003 
Gupta S, Chaturvedi P, Kulkarni MG, Van Staden J (2020) A critical review on exploiting the pharmaceutical potential of plant endophytic fungi. Biotechnol. Adv. 39, 107462.

https://doi.org/10.1016/j.biotechadv.2019.107462

Harburguer LV, Seccacini E, Masuh H (2009) Thermal behaviour and biological activity against Aedes aegypti (Diptera: Culicidae) of permethrin and pyriproxyfen in a smoke-generating formulation. Pest Manag. Sci. 65, 1208-1214. https://doi.org/10.1002/ps.1811

Harel M, Kryger G, Rosenberry TL (2000) Three-dimensional structures of Drosophila melanogaster acetylcholinesterase and of its complexes with two potent inhibitors . Protein Sci. 9, 1063-1072. https://doi.org/10.1110/ps.9.6.1063

Hoffman AM, Mayer SG, Strobel GA et al (2008) Purification, identification and activity of phomodione, a furandione from an endophytic Phoma species. Phytochemistry 69:1049-1056.

https://doi.org/10.1016/j.phytochem.2007.10.031

Holanda FH, Birolli WG, Ferreira IM (2019) Study of biodegradation of chloramphenicol by endophytic fungi isolated from Bertholletia excelsa (Brazil nuts). Biocatal. Agric. Biotechnol. 20:101200. https://doi.org/10.1016/j.bcab.2019.101200

Hu ZY, Li YY, Huang YJ (2008) Three new sesquiterpenoids from Xylaria sp. NCY2. Helv. Chim. Acta 91:46-52. https://doi.org/10.1002/hlca.200890011

Ibrahim SRM, Elkhayat ES, Mohamed GA et al (2015) Aspernolides F and G, new butyrolactones from the endophytic fungus Aspergillus terreus. Phytochem. Lett. 14:84-90.

https://doi.org/10.1016/j.phytol.2015.09.006

Isaka M, Berkaew P, Intereya K, Komwijit S, Sathitkunanon T (2007) Antiplasmodial and antiviral cyclohexadepsipeptides from the endophytic fungus Pullularia sp. BCC 8613. Tetrahedron 63:68556860. https://doi.org/10.1016/j.tet.2007.04.062

Ivanova L, Skjerve E, Eriksen GS, Uhlig S (2006) Cytotoxicity of enniatins A, A1, B, B1, B2 and B3 from Fusarium avenaceum. Toxicon 47:868-876. https://doi.org/10.1016/j.toxicon.2006.02.012

Jonsson M, Jestoi M, Anthoni M, Welling A, Loivamaa I et al (2016) Fusarium mycotoxin enniatin B: Cytotoxic effects and changes in gene expression profile. Toxicol. Vitr. 34:309-320. https://doi.org/10.1016/j.tiv.2016.04.017

Kim IH, Pham V, Jablonka W (2017) A mosquito hemolymph odorant-binding protein family member specifically binds juvenile hormone. J. Biol. Chem. 292, 15329-15339.

https://doi.org/10.1074/jbc.M117.802009

Kirchmair J, Göller AH, Lang D et al (2015) Predicting drug metabolism: Experiment and/or computation? Nat. Rev. Drug Discov. 14, 387-404. https://doi.org/10.1038/nrd4581 
Kraemer MUG, Sinka ME, Duda KA et al 2015. The global distribution of the arbovirus vectors Aedes aegypti and Ae. Albopictus. Elife 4:1-18. https://doi.org/10.7554/eLife.08347

Kumar P, Singh B, Thakur V (2019) Hyper-production of taxol from Aspergillus fumigatus, an endophytic fungus isolated from Taxus sp. of the Northern Himalayan region. Biotechnol. Reports 24:00395. https://doi.org/10.1016/j.btre.2019.e00395

Kuo CT, Liu TH, Hsu TH et al (2015) Antioxidant and antiglycation properties of different solvent extracts from Chinese olive (Canarium album L.) fruit. Asian Pac. J. Trop. Med. 8:1013-1021. https://doi.org/10.1016/j.apjtm.2015.11.013

Linnakoski R, Reshamwala D, Vetel P (2018) Antiviral agents from fungi: Diversity, mechanisms and potential applications. Front. Microbiol. 9. https://doi.org/10.3389/fmicb.2018.02325

Lo MK, Jordan R, Arvey A, et al (2017) GS-5734 and its parent nucleoside analog inhibit Filo, Pneumo-, and Paramyxoviruses. Sci. Rep. 7:1-7. https://doi.org/10.1038/srep43395

Macari PAT, Sousa RR De, Crespo MLL et al (2002) Comparação entre os metais presentes em Croton floribundus Spreng. e Baccharis dracunculifolia DC. Rev. Bras. Farmacogn. 12, 76-77. https://doi.org/10.1590/S0102-695X2002000300037

Martínez-Culebras PV, Crespo-Sempere A, Sánchez-Hervás M (2009) Molecular characterization of the black Aspergillus isolates responsible for ochratoxin A contamination in grapes and wine in relation to taxonomy of Aspergillus section Nigri. Int. J. Food Microbiol. 132:33-41.

https://doi.org/10.1016/j.jffoodmicro.2009.03.015

Meriç A (2017). Molecular modelling of 2-iminothiazoles as insecticidal activity 49:5-14.

Michaelakis A, Papachristos DP, Rumbos Cl et al (2020) Larvicidal activity of spinosad and its impact on oviposition preferences of the West Nile vector Culex pipiens biotype molestus - A comparison with a chitin synthesis inhibitor. Parasitol. Int. 74, 101917. https://doi.org/10.1016/j.parint.2019.04.014

Mikawlrawng K (2016) Aspergillus in Biomedical Research, New and Future Developments in Microbial Biotechnology and Bioengineering: Aspergillus System Properties and Applications. Elsevier B.V. https://doi.org/10.1016/B978-0-444-63505-1.00019-1

Ministério da Saúde, 2020. Monitoramento dos casos de Arboviroses urbanas transmitidas pelo Aedes (dengue, chikungunya e Zika). Bol. Epidemiológico Arboviroses 51:1-13.

Montenegro LHM, Oliveira PES, Conserva LM et al (2006) Terpenóides e avaliação do potencial antimalárico, larvicida, anti-radicalar e anticolinesterásico de Pouteria venosa (Sapotaceae). Rev. Bras. Farmacogn. 16, 611-617. https://doi.org/10.1590/s0102-695x2006000500005 
Mookherjee A, Mitra M, Kutty NN, Mitra A, Maiti MK (2020) Characterization of endo-metabolome exhibiting antimicrobial and antioxidant activities from endophytic fungus Cercospora sp. PM018. South African J. Bot. 000:1-9. https://doi.org/10.1016/j.sajb.2020.01.040

Olmstead AW, LeBlanc GA (2003) Insecticidal juvenile hormone analogs stimulate the production of male offspring in the crustacean Daphnia magna. Environ. Health Perspect. 111: 919-924.

https://doi.org/10.1289/ehp.5982

Parvatkar RR, D'Souza C, Tripathi A, Naik CG (2009) Aspernolides A and B, butenolides from a marinederived fungus Aspergillus terreus. Phytochemistry 70:128-132.

https://doi.org/10.1016/j.phytochem.2008.10.017

Pascini TV, Ramalho-Ortigão M, Martins GF (2012) Morphological and morphometrical assessment of spermathecae of Aedes aegypti females. Mem. Inst. Oswaldo Cruz 107:705-712.

https://doi.org/10.1590/S0074-02762012000600001

Patil RH, Patil MP, Maheshwari VL (2016) Bioactive Secondary Metabolites From Endophytic Fungi: A Review of Biotechnological Production and Their Potential Applications. Stud. Nat. Prod. Chem. 49:189205. https://doi.org/10.1016/B978-0-444-63601-0.00005-3

Paul A, Harrington LC, Scott JG (2006) Evaluation of novel insecticides for control of dengue vector Aedes aegypti (Diptera: Culicidae). J. Med. Entomol. 43:55-60. https://doi.org/10.1093/jmedent/43.1.55

Pliego-Pliego E, Vasilieva O, Velázquez-Castro J, Fraguela Collar A (2020) Control strategies for a population dynamics model of Aedes aegypti with seasonal variability and their effects on dengue incidence. Appl. Math. Model. 81:296-319. https://doi.org/10.1016/j.apm.2019.12.025

Pradeep FS, Palaniswamy M, Ravi S, Thangamani A, Pradeep BV (2015) Larvicidal activity of a novel isoquinoline type pigment from Fusarium moniliforme KUMBF1201 against Aedes aegypti and Anopheles stephensi. Process Biochem. 50:1479-1486. https://doi.org/10.1016/j.procbio.2015.05.022

Ragavendran C, Dubey NK, Natarajan D (2017) Beauveria bassiana (Clavicipitaceae): a potent fungal agent for controlling mosquito vectors of Anopheles stephensi, Culex quinquefasciatus and Aedes aegypti (Diptera: Culicidae). RSC Adv. 7:3838-3851. https://doi.org/10.1039/C6RA25859J

Ramos RS, Costa JS, Silva RC et al (2019) Identification of potential inhibitors from pyriproxyfen with insecticidal activity by virtual screening. Pharmaceuticals 12. https://doi.org/10.3390/ph12010020

Rana KL, Kour D, Kaur T, Devi R et al (2020). Endophytic fungi from medicinal plants: biodiversity and biotechnological applications, Microbial Endophytes. Elsevier Inc. https://doi.org/10.1016/b978-0-12819654-0.00011-9

Renaud JB, Kelman MJ, McMullin DR, Yeung KKC, Sumarah MW (2017) Application of C8 liquid chromatography-tandem mass spectrometry for the analysis of enniatins and bassianolides. J. 
Chromatogr. A 1508, 65-72. https://doi.org/10.1016/j.chroma.2017.05.070

Revathi K, Chandrasekaran R, Thanigaivel A, et al (2013) Effects of Bacillus subtilis metabolites on larval Aedes aegypti L. Pestic. Biochem. Physiol. 107:369-376. https://doi.org/10.1016/j.pestbp.2013.10.005

Rocha HDR, Paiva MHS, Silva NM (2015) Susceptibility profile of Aedes aegypti from Santiago Island, Cabo Verde, to insecticides. Acta Trop. 152:66-73. https://doi.org/10.1016/j.actatropica.2015.08.013

Rodrigues ECR, Ferreir AM (2014) Development of a larvicidal nanoemulsion with Copaiba (Copaifera duckei) oleoresin. Brazilian J. Pharmacogn. 24:699-705. https://doi.org/10.1016/j.bjp.2014.10.013

Samson RA, Visagie CM, Houbraken J (2014) Phylogeny, identification and nomenclature of the genus Aspergillus. Stud. Mycol. 78:141-173. https://doi.org/10.1016/j.simyco.2014.07.004

Santos GKN, Dutra KA, Barros RA, et al (2012) Essential oils from Alpinia purpurata (Zingiberaceae): Chemical composition, oviposition deterrence, larvicidal and antibacterial activity. Ind. Crops Prod. 40:254-260. https://doi.org/10.1016/j.indcrop.2012.03.020

Siegel D, Hui HC, Doerffler E et al (2017) Discovery and Synthesis of a Phosphoramidate Prodrug of a Pyrrolo[2,1-f] [triazin-4-amino] Adenine C-Nucleoside (GS-5734) for the Treatment of Ebola and Emerging Viruses. J. Med. Chem. 60:1648-1661. https://doi.org/10.1021/acs.jmedchem.6b01594

Sivanathan S, Scherkenbeck J (2014) Cyclodepsipeptides: A rich source of biologically active compounds for drug research. Molecules 19:12368-12420. https://doi.org/10.3390/molecules190812368

Smith LB, Kasai S, Scott JG (2016) Pyrethroid resistance in Aedes aegypti and Aedes albopictus: Important mosquito vectors of human diseases. Pestic. Biochem. Physiol. 133:1-12. https://doi.org/10.1016/j.pestbp.2016.03.005

Soltani J (2016) Secondary Metabolite Diversity of the Genus Aspergillus: Recent Advances, New and Future Developments in Microbial Biotechnology and Bioengineering: Aspergillus System Properties and Applications. Elsevier B.V. https://doi.org/10.1016/B978-0-444-63505-1.00035-X

Soonwera M, Phasomkusolsil S (2017) Adulticidal, larvicidal, pupicidal and oviposition deterrent activities of essential oil from Zanthoxylum limonella Alston (Rutaceae) against Aedes aegypti (L.) and Culex quinquefasciatus (Say). Asian Pac. J. Trop. Biomed. 7:967-978.

https://doi.org/10.1016/j.apjtb.2017.09.019

Strobel G (2012) Genetic Diversity of Microbial Endophytes and Their Biotechnical Applications, in: Genomics Applications for the Developing World. Advances in Microbial Ecology. 161-182. https://doi.org/10.1007/978-1-4614-2182-5

Subban K, Subramani R, Madambakkam Srinivasan VP (2019) Salicylic acid as an effective elicitor for improved taxol production in endophytic fungus Pestalotiopsis microspora. PLoS One 14:1-17. 
https://doi.org/10.1371/journal.pone.0212736

Sullivan JJ, Goh KS (2008) Environmental fate and properties of pyriproxyfen. J. Pestic. Sci. 33:339-350. https://doi.org/10.1584/jpestics.R08-02

Tilak R, Gupta V, Suryam V, Yadav JD, Gupta KKD (2005) A laboratory investigation into oviposition responses of Aedes aegypti to some common household substances and water from conspecific larvae. Med. J. Armed Forces India 61:227-229. https://doi.org/10.1016/S0377-1237(05)80159-5

Ureña E, Guillem-Amat A, Couso-Ferrer F et al (2019) Multiple mutations in the nicotinic acetylcholine receptor Cca6 gene associated with resistance to spinosad in medfly. Sci. Rep. 9, 1-12. https://doi.org/10.1038/s41598-019-38681-w

Valotto CFB, da Silva HHG, Cavasin G et al (2011) Alterações ultraestruturais em larvas de Aedes aegypti submetidas ao diterpeno labdano, isolado de Copaifera reticulata (Leguminosae), e à uma fração rica em taninos de Magonia pubescens (Sapindaceae). Rev. Soc. Bras. Med. Trop. 44:194-200.

https://doi.org/10.1590/S0037-86822011005000010

Varga J, Frisvad JC, Kocsubé S (2011) New and revisited species in Aspergillus section Nigri. Stud. Mycol. 69:1-17. https://doi.org/10.3114/sim.2011.69.01

Visagie CM, Houbraken J, Frisvad JC (2014) Identification and nomenclature of the genus Penicillium. Stud. Mycol. 78:343-371. https://doi.org/10.1016/j.simyco.2014.09.001

Warren TK, Jordan R, Lo MK et al (2016) Therapeutic efficacy of the small molecule GS-5734 against Ebola virus in rhesus monkeys. Nature 531:381-385. https://doi.org/10.1038/nature17180

World Health Organization, 2005. Guidelines for laboratory and field testing of mosquito larvicides 1-41.

Yang J (2009) Brazil nuts and associated health benefits: A review. LWT - Food Sci. Technol. 42:15731580. https://doi.org/10.1016/j.Iwt.2009.05.019

Yang, S., Bai, M., Yang, J., Yuan, Y., Zhang, Y., Qin, J., Kuang, Y., Sampietro, D.A., 2020. Chemical composition and larvicidal activity of essential oils from Peganum harmala, Nepeta cataria and Phellodendron amurense against Aedes aegypti (Diptera: Culicidae). Saudi Pharm. J. 28, 560-564. https://doi.org/10.1016/j.jsps.2020.03.007

Yokoyama K, Wang L, Miyaji M, Nishimura K (2001) Identification, classification and phylogeny of the Aspergillus section Nigri inferred from mitochondrial cytochrome $\beta$ gene. FEMS Microbiol. Lett. 200:241246. https://doi.org/10.1111/j.1574-6968.2001.tb10722.x

Zhang P, Li XM, Wang JN, Li X, Wang BG (2015) New butenolide derivatives from the marine-derived fungus Paecilomyces variotii with DPPH radical scavenging activity. Phytochem. Lett. 11:85-88. https://doi.org/10.1016/j.phytol.2014.11.014 
Zhu L Chen L (2019) Progress in research on paclitaxel and tumor immunotherapy. Cell. Mol. Biol. Lett. 24:1-11. https://doi.org/10.1186/s11658-019-0164-y

Zuharah WF, Ling CJ, Zulkifly N, Fadzly N (2015) Toxicity and sub-lethal effect of endemic plants from family Anacardiaceae on oviposition behavior of Aedes albopictus. Asian Pac. J. Trop. Biomed. 5:612618. https://doi.org/10.1016/j.apjtb.2015.03.012

\section{Tables}

Tabela 1- Protocols data used for molecular docking validation.

\begin{tabular}{|c|c|c|c|}
\hline Enzyme & Inhibitor & Grid center & $\begin{array}{l}\text { Grid size } \\
\text { (points) }\end{array}$ \\
\hline \multirow{4}{*}{$\begin{array}{l}\text { AChE } \\
\text { (PDB code: } \\
\text { 4EY6) }\end{array}$} & \multirow[t]{4}{*}{ (-)-Galanthamine } & \multirow{2}{*}{$\begin{array}{l}X= \\
-10.733\end{array}$} & $60 x$ \\
\hline & & & $32 y$ \\
\hline & & -43.626 & $24 z$ \\
\hline & & $Z=29.535$ & \\
\hline \multirow{3}{*}{$\begin{array}{l}\text { AChE } \\
\text { (PDB code: } \\
\text { 1QON) }\end{array}$} & \multirow{3}{*}{$\begin{array}{l}\text { 9-(3-lodobenzylamino)-1,2,3,4- } \\
\text { Tetrahydroacridine }\end{array}$} & $X=33.218$ & $60 x$ \\
\hline & & $Y=67.677$ & $32 y$ \\
\hline & & $Z=9.118$ & $26 z$ \\
\hline \multirow{3}{*}{$\begin{array}{l}\text { Juvenile } \\
\text { hormone } \\
\text { (PDB code: } \\
\text { 5V13) }\end{array}$} & $\begin{array}{l}\text { methyl (2E,6E)-9-[(2R)-3,3-dimethyloxiran-2- } \\
\text { yl]-3, }\end{array}$ & $\begin{array}{l}X= \\
214.732\end{array}$ & \multirow{2}{*}{$\begin{array}{l}60 x \\
36 y\end{array}$} \\
\hline & \multirow[t]{2}{*}{ 7-dimethylnona-2,6-dienoate } & $Y=2.286$ & \\
\hline & & $\begin{array}{l}Z= \\
353.677\end{array}$ & $24 z$ \\
\hline
\end{tabular}

Table 2. Compounds identified by LC-MS / MS from the crude extract of Aspergillus sp. isolated from Bertholletia excelsa. 


\begin{tabular}{|c|c|c|c|c|}
\hline Number & Compound & $\begin{array}{l}\text { Empirical } \\
\text { formula }\end{array}$ & Estrutura química & $\begin{array}{c}\text { Expected } \\
\text { neutral mass }\end{array}$ \\
\hline & & & & 168.115029755 \\
\hline 01 & 2-deceno- $d$-lactone & $\mathrm{C}_{10} \mathrm{H}_{10} \mathrm{O}_{2}$ & & \\
\hline 02 & Methyl jasponic & $\mathrm{C}_{13} \mathrm{H}_{20} \mathrm{O}_{3}$ & & 224.1412445049 \\
\hline 03 & 2-heptyloctahydro- & $\mathrm{C}_{16} \mathrm{H}_{20} \mathrm{O}_{3}$ & & 270.2194948239 \\
\hline 04 & Aspergillol B & $\mathrm{C}_{16} \mathrm{H}_{16} \mathrm{O}_{4}$ & & 272.1048589996 \\
\hline 05 & Aspemolide A & $\mathrm{C}_{24} \mathrm{H}_{24} \mathrm{O}_{7}$ & & 424.1522031217 \\
\hline & $(+)-N-$ & & & 443.2671732992 \\
\hline 06 & deoxymilitarinone $\mathrm{A}$ & $\mathrm{C}_{26} \mathrm{H}_{37} \mathrm{NO}_{5}$ & & \\
\hline
\end{tabular}


07

Aspulvinone $\mathrm{C} \quad \mathrm{C}_{27} \mathrm{H}_{28} \mathrm{O}_{s}$

OS

Aspulvinone D $\quad \mathrm{C}_{27} \mathrm{H}_{23} \mathrm{O}_{3}$

09

10

Emniatin A $\quad \mathrm{C}_{53} \mathrm{H}_{61} \mathrm{~N}_{3} \mathrm{O}_{3}$

11

Paclitaxsel

$\mathrm{C}_{47} \mathrm{H}_{31} \mathrm{NO}_{14}$

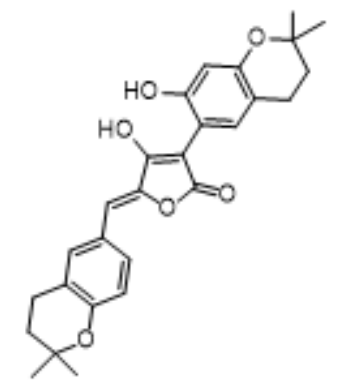

448.188588627

448.188588627

667.4407805688

681.4564306326

853.3309553465

Table 3. Larvicidal activity $\left(\mathrm{LC}_{50}\right.$ and $\left.\mathrm{LC}_{90}\right)$ for Aedes aegypti in 24 and 48 hours. 


\begin{tabular}{|lll|}
\hline Aspergillus sp. & Aedes aegypti \\
\hline & $24 \mathrm{~h}$ & $48 \mathrm{~h}$ \\
\hline $\mathrm{LC}_{50}(\mu \mathrm{g} / \mathrm{mL})$ & 26.86 & 18.75 \\
\hline $\mathrm{C} . \mathrm{I}(\mu \mathrm{g} / \mathrm{mL})$ & $19.98 \pm 35.28$ & $11.12 \pm 25.88$ \\
\hline $\mathrm{LC}{ }_{90}(\mu \mathrm{g} / \mathrm{mL})$ & 47.55 & 38.55 \\
\hline $\mathrm{C} . \mathrm{I}(\mu \mathrm{g} / \mathrm{mL})$ & $38.20 \pm 70.27$ & $30.55 \pm 59.64$ \\
\hline
\end{tabular}

*. C.I. = confidence interval

Table 4- Biological activity prediction of the molecules selected by virtual screening approaches.

\begin{tabular}{|llll|}
\hline Inhibitors & $\mathrm{Pa}^{1}$ & $\mathrm{Pi}^{2}$ & Biological activity \\
\hline Pyriproxyfen & 0.586 & 0.003 & Insecticide \\
\hline GNT & 0.376 & 0.154 & $\begin{array}{l}\text { Acetylcholine neuromuscular } \\
\text { blocking agente }\end{array}$ \\
\hline I40 & & & Acetylcholine transporter \\
& 0.025 & 0.005 & Inhibitor \\
\hline JHIII & & & Insecticide \\
\hline Aspulvinone D & - & - & - \\
\hline Aspulvinone C & - & - & - \\
\hline Aspergillol B & 0,187 & 0,042 & Insecticide \\
\hline Aspernolide A & - & - & - \\
\hline (+)-N-deoxymilitarinone & - & - & - \\
\hline
\end{tabular}

1-probability to be active; 2-probability to be inactive.

\section{Figures}




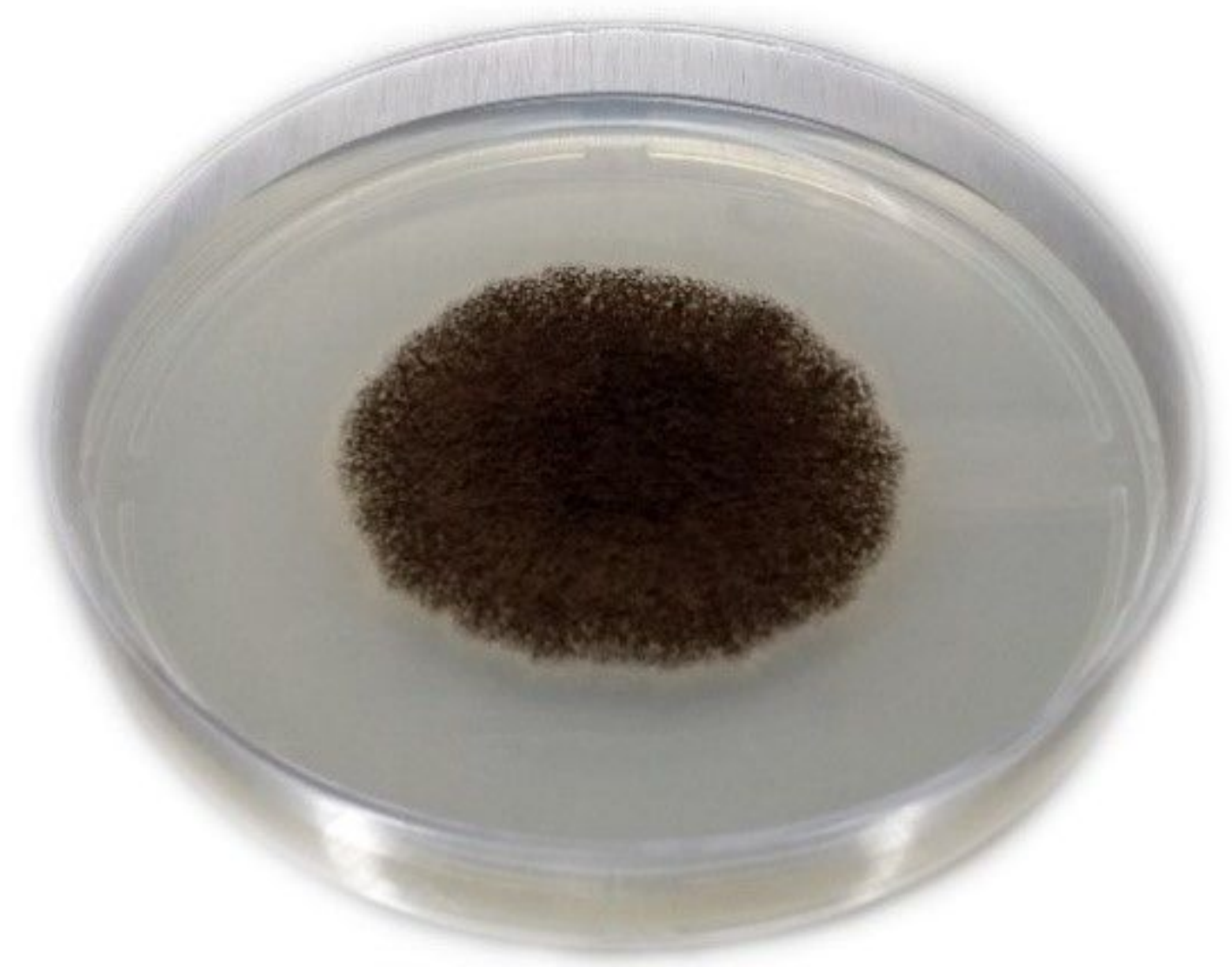

Figure 1

Fungus Aspergillus sp. isolated from Bertholletia excelsa Humn. \& Bonpl. 

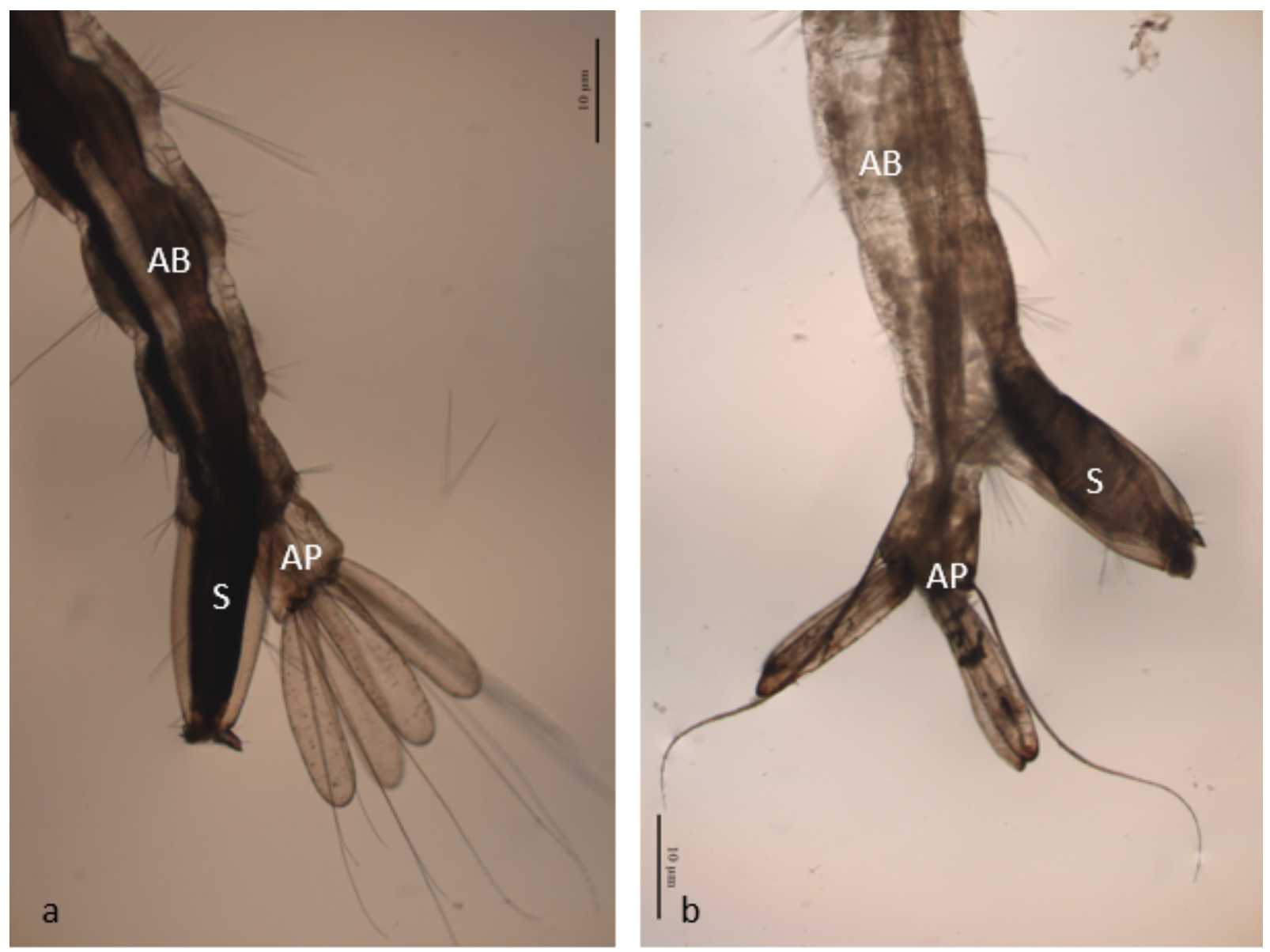

\section{Figure 2}

Control Aedes aegypti larva (a) and treated with crude extract of Aspergillus sp (b) presenting the following abdomen (AB), anal papilla (AP) and respiratory siphon (S) structures.

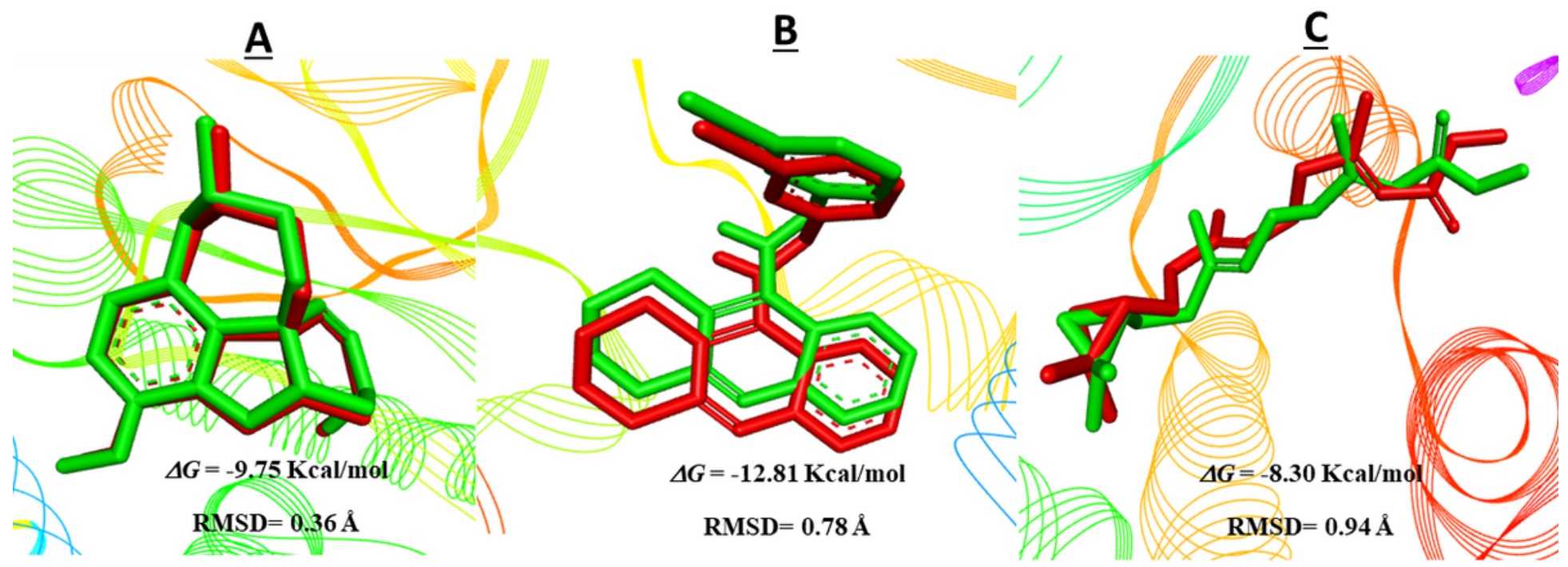

Figure 3 
Shapes overlay of crystallographic ligands (in green) with the calculated shape (in red): (A) GNT and (B) 140 and (C) JHIII.
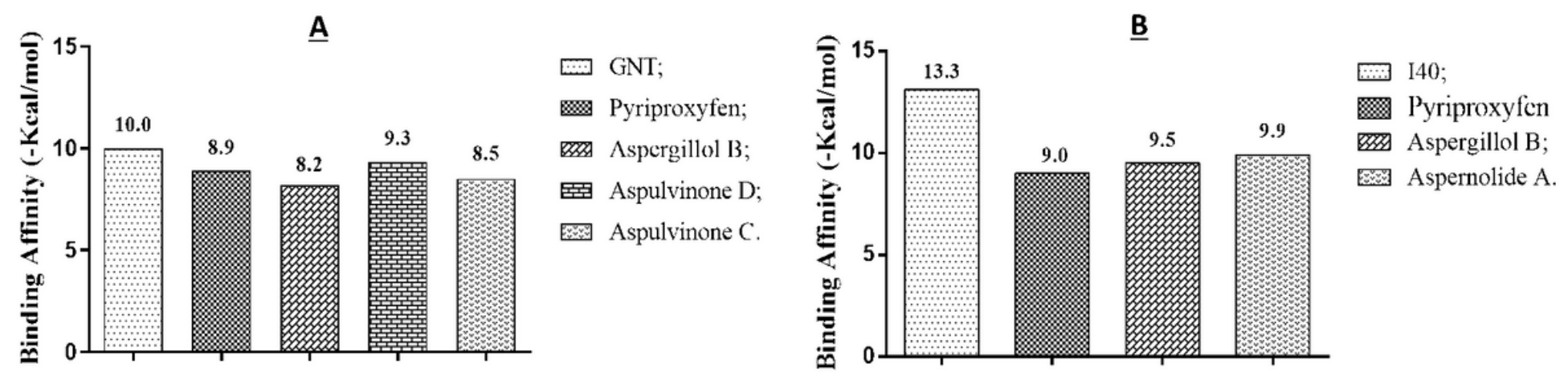

Figure 4

Results of binding affinity of the compounds with (A) human acetylcholinesterase; (B) insect acetylcholinesterase.

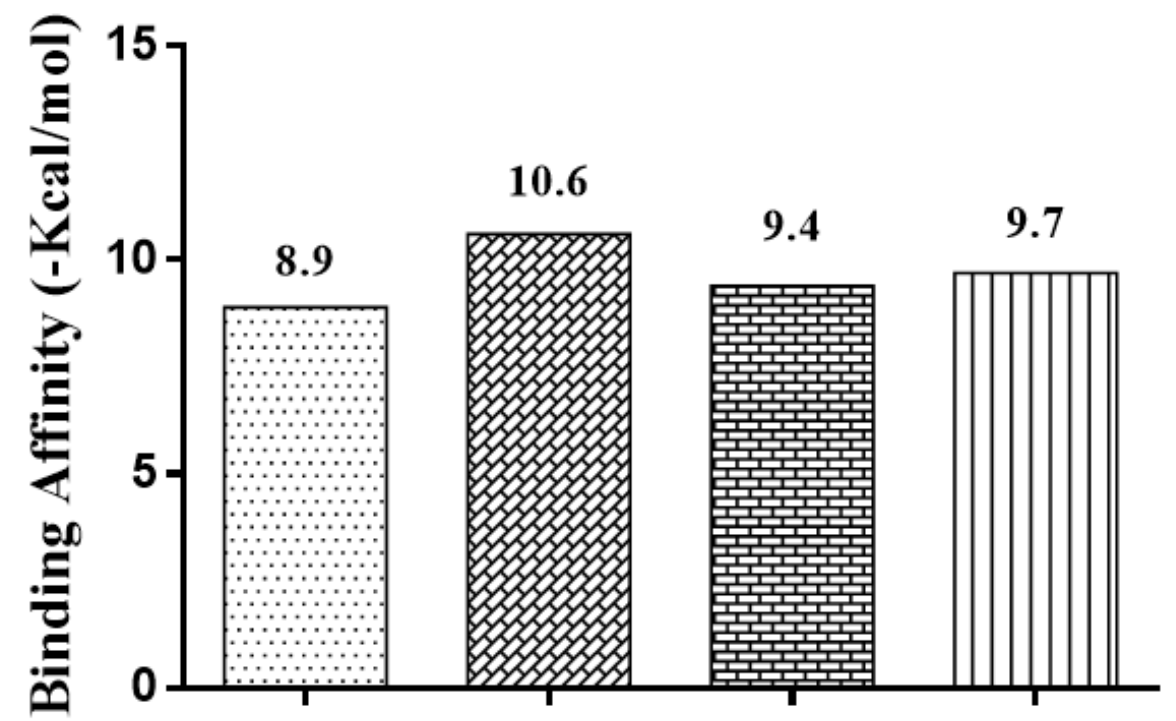

…… JHIII;

Pyriproxyfen;

臣空 Aspergillol B;

एा (+)-N-deoxymilitarinone.

Figure 5

Results of binding affinity of the compounds with the juvenile hormone receptor. 

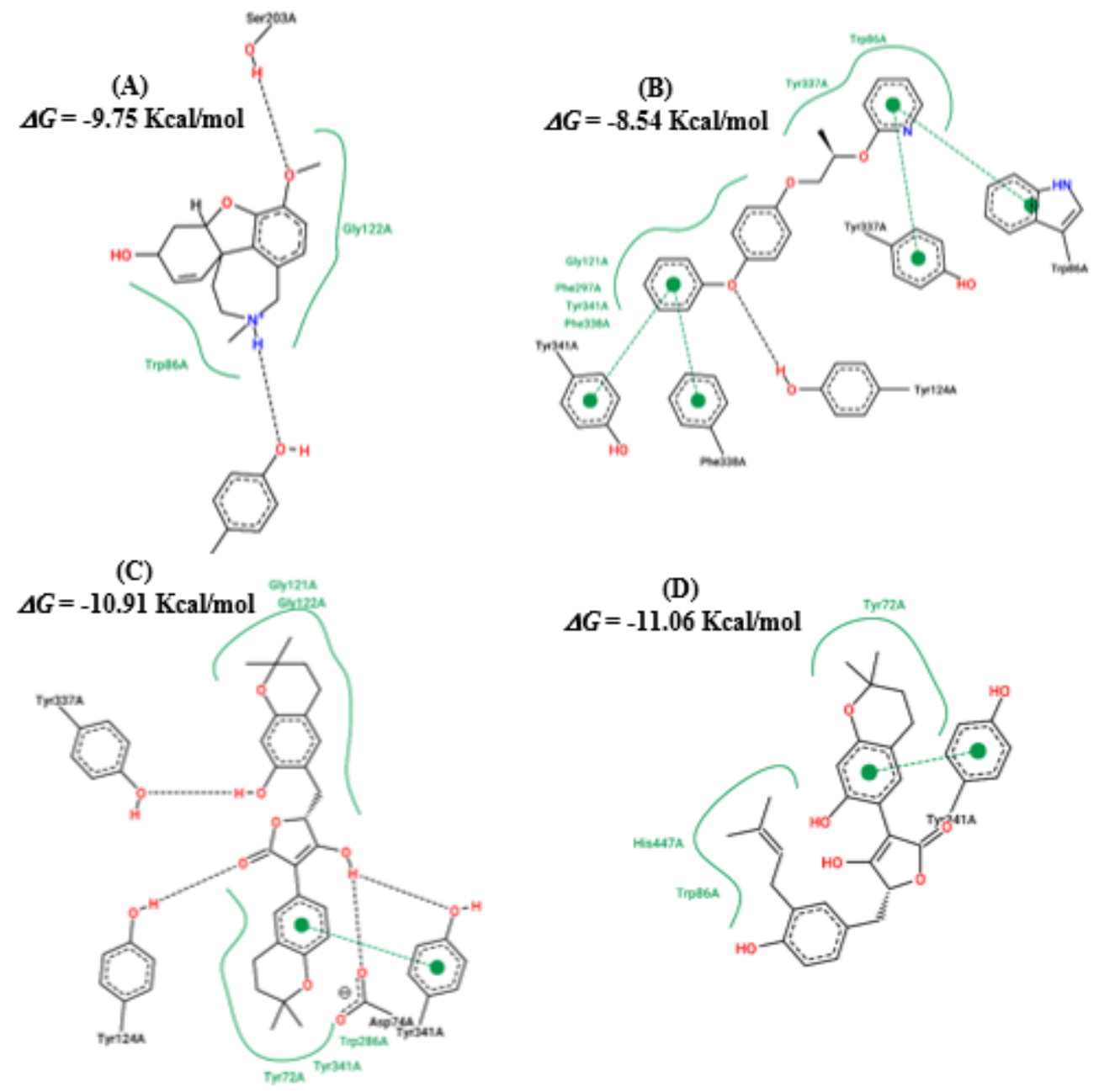

${ }^{*}$ Dashed black lines indicate hydrogen bonds, saline bridges and interactions with metal. Solid green lines show hydrophobic interactions and the dashed green lines show $\pi-\pi$ and $\pi$-cations interactions.

\section{Figure 6}

Interactions of GNT (A), Pyriproxyfen (B) and potential inhibitors Aspulvinone C (C) and Aspulvinone D (D) with active site of the acetylcholinesterase receptor. * 
(A)

$\Delta G=-12.81 \mathrm{Kcal} / \mathrm{mol}$

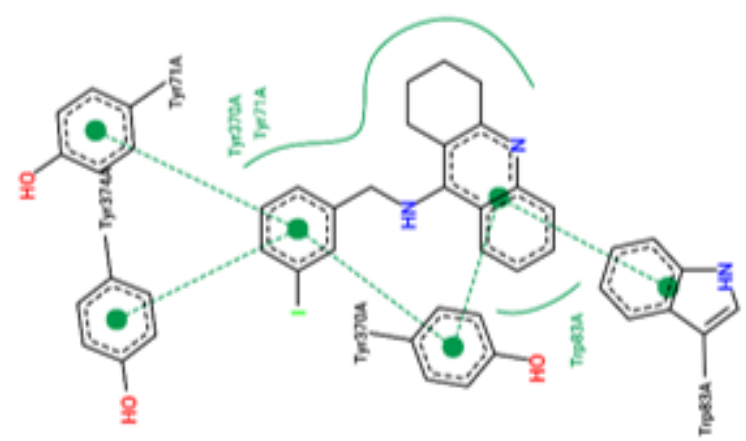

(C)

$\Delta G=-7.74 \mathrm{Kcal} / \mathrm{mol}$

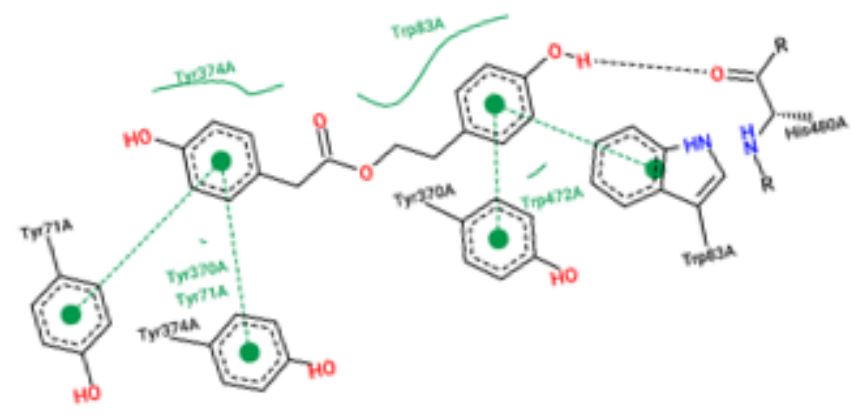

(B)

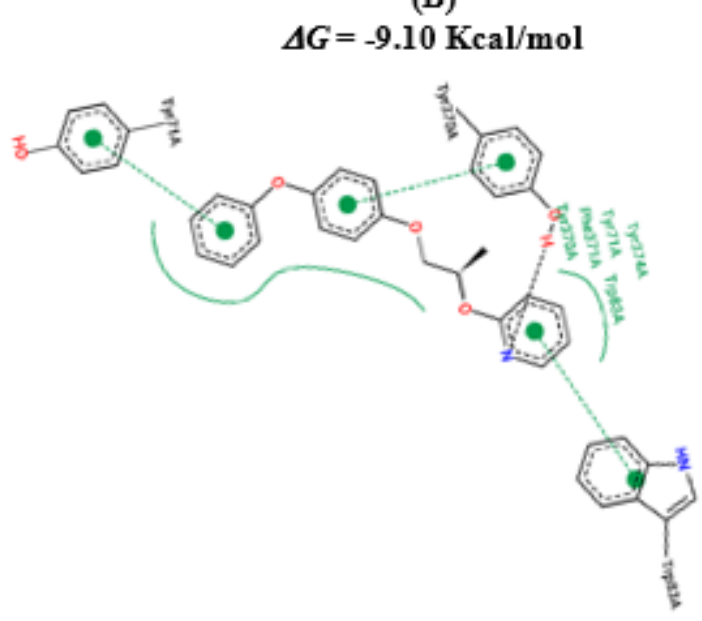

(D)

$\Delta G=-9.35 \mathrm{Kcal} / \mathrm{mol}$

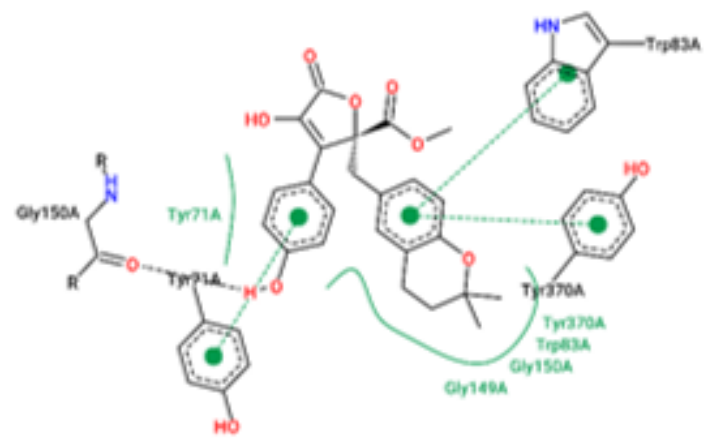

Figure 7

Interactions of controls 140 (A), Pyriproxyfen (B) and potential inhibitors Aspergillus B (C) and Aspernolide $A(D)$ with insect acetylcholinesterase active site. 
(A)

$\Delta G=-12.81 \mathrm{Kcal} / \mathrm{mol}$

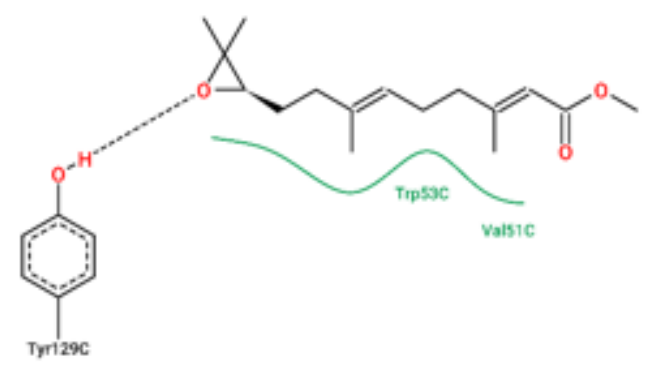

(C)

$\Delta G=-8.57 \mathrm{Kcal} / \mathrm{mol}$

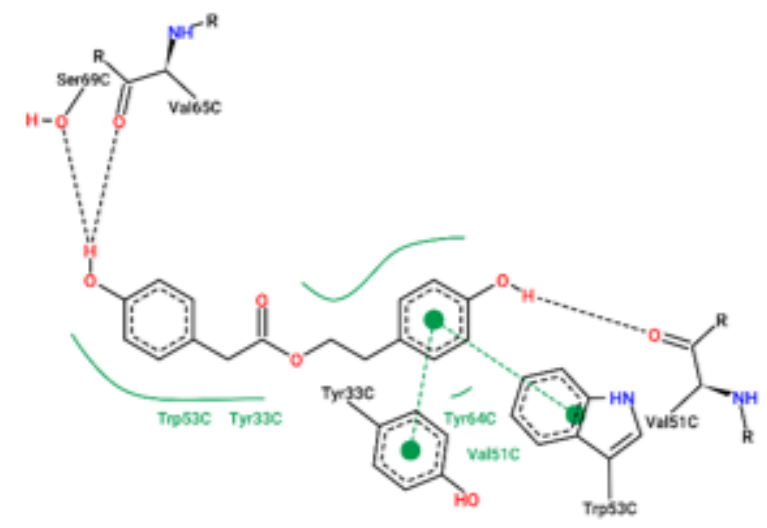

(B) $\Delta G=-10.79 \mathrm{Kcal} / \mathrm{mol}$

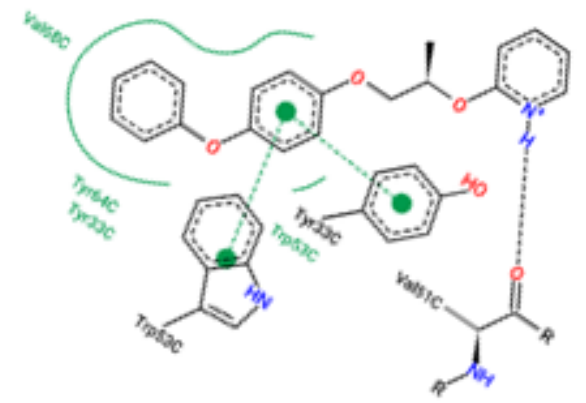

(D) $\Delta G=-11.79 \mathrm{Kcal} / \mathrm{mol}$

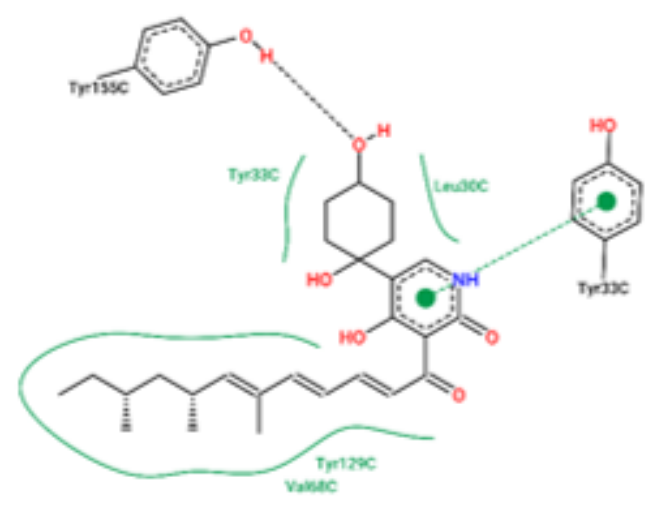

\section{Figure 8}

Interactions of the controls JHIII (A), Pyriproxyfen (B) and potential inhibitors Aspergillol B (C) and (+) $-\mathrm{N}-$ deoxymilitarinone (D) with active site of juvenile hormone receptor.

\section{Supplementary Files}

This is a list of supplementary files associated with this preprint. Click to download.

- GA.png 